\title{
CORRECTION
}

\section{Correction to: Oliceridine: First Approval}

\author{
Anthony Markham ${ }^{1}$
}

Published online: 19 October 2020

(c) Springer Nature Switzerland AG 2020

\section{Correction to: Drugs (2020)}

https://doi.org/10.1007/s40265-020-01414-9

Table entitled Features and properties of oliceridine, first row, which currently reads:

$$
\text { Alternative names } \quad \text { OLINVO; OLINVYK; TRV 130A; TRV-130 }
$$

Should read:

Alternative names

OLINVYK; TRV 130A; TRV-130

The original article has been updated.

The original article can be found online at https://doi.org/10.1007/ s40265-020-01414-9.

$\triangle$ Anthony Markham dru@adis.com

1 Springer Nature, Mairangi Bay, Private Bag 65901, Auckland 0754, New Zealand 